IFAS Extension

\title{
Gardening in Raised Beds ${ }^{1}$
}

\author{
Terry Brite DelValle ${ }^{2}$
}

Gardening in raised beds is becoming more popular as more people try growing their own food. Using raised beds is like growing plants in large containers. The planting area is raised above the existing soil level and usually enclosed within a structure to form a planting bed.

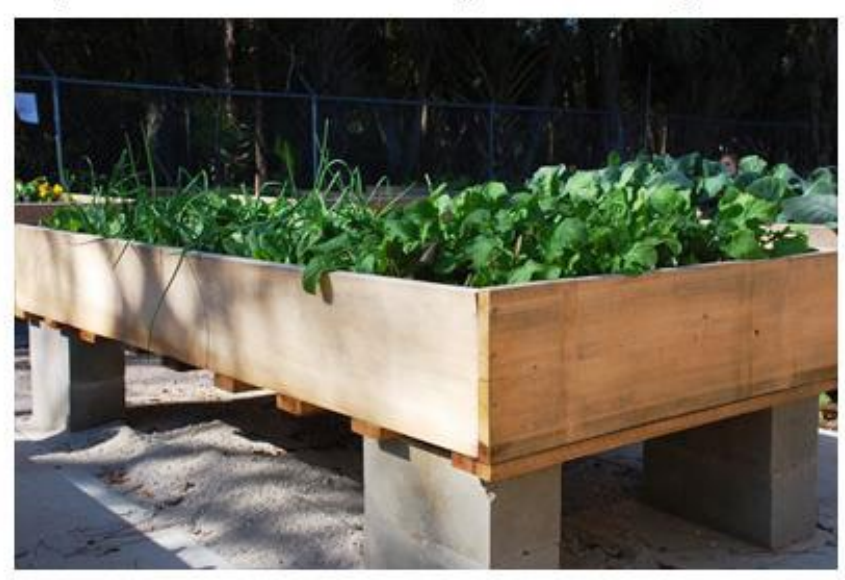

Figure 1. Example of an elevated raised bed ideal for individuals in wheel chairs or for those who can't bend over.

Credits: Terry DelValle

Raised beds offer many advantages. Traditional gardening takes a toll on knees and backs, whereas gardening in raised beds helps save the joints (Fig. 1). Many gardeners cannot grow vegetables in traditional gardens because soils are poor, too wet, compacted, or plagued with nematodes and other soilborne pests. Raised beds allow you to control the soil to avoid these issues. Another plus is that soils aboveground heat up more quickly so you can get a jump on the spring gardening season. Also, raised beds are typically more productive than in-ground vegetable gardens because the planting medium is easier to improve and there is no wasted space for walkways between rows.

\section{Getting Started}

Select a location that receives at least 6-8 hours of direct sun and is close to a water source. Find a level area for the raised bed or one where minor modifications will make it level. If the area has turf, remove the top layer of grass or place recycled cardboard or multiple layers of black and white newspaper on top to suppress the existing grass or weeds.

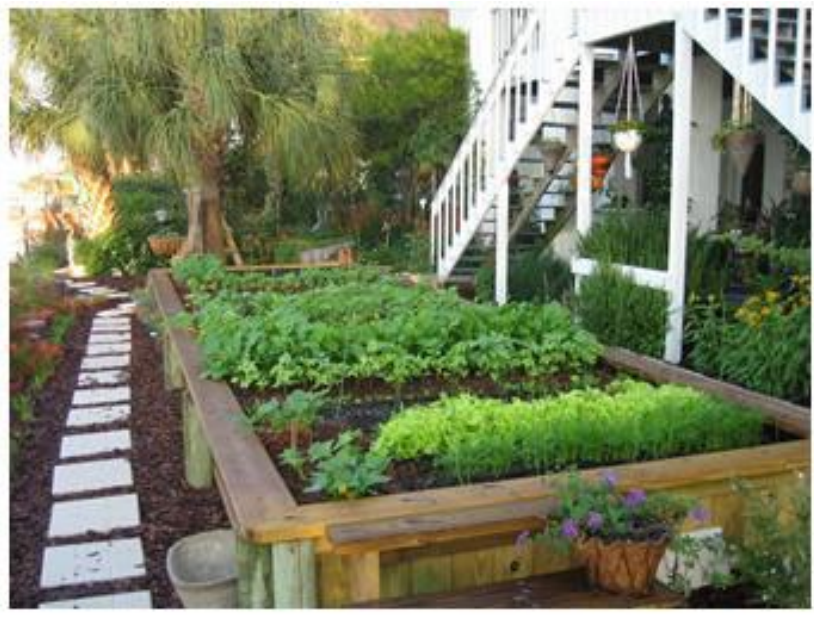

Figure 2. Raised beds can be elaborate and esthetically pleasing. Credits: Aline Clement, Duval County Master Gardener

1. This document is ENH1211, one of a series of the Environmental Horticulture Department, Florida Cooperative Extension Service, Institute of Food and Agricultural Sciences, University of Florida. Original publication date May 2013. Visit the EDIS website at http://edis.ifas.ufl.edu.

2. Terry Brite DelValle, Duval County urban horticulture Extension agent, Florida Cooperative Extension Service, Institute of Food and Agricultural Sciences, University of Florida, Gainesville, FL 32611. 
Next, determine the size and height of the raised bed. It should be no wider than 4' because most people can only comfortably reach 2 ' to the center. The length varies and depends on the site. A common size is 4' wide $\mathrm{x} 8$ ' long $\mathrm{x}$ 16 "-24" deep. The height really depends on the level that is most comfortable for you and the investment you want to make in materials. The site may lend itself to multiple beds but make sure to give yourself ample room between beds-about 18"-24". Beds can be various shapes (e.g., square, rectangle, $\mathrm{L}$ shaped, triangle). Raised beds can be basic or very elaborate and esthetically pleasing in the landscape (Fig. 2).

\section{Materials}

Options for building materials include stone, bricks, concrete blocks, synthetic/recycled materials, or wood. Wood is the most common material and is relatively inexpensive, but untreated lumber starts to rot within a year. For longevity and cost effectiveness, use ACQ Ground Contact treated lumber, which is treated with new copper preservatives and approved by the Food and Drug Administration for food production. Cedar, redwood, and synthetic wood (Fig. 3) are also durable, but they are more expensive than ACQ treated lumber. Avoid using railroad ties or old pressuretreated lumber purchased prior to 2004 for edibles because of the potential for food contamination from creosote and arsenic.

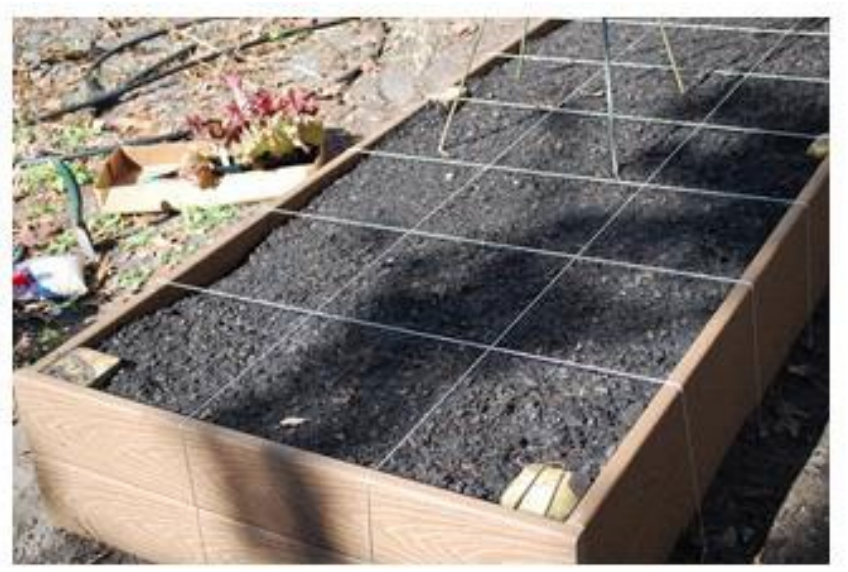

Figure 3. A raised bed using synthetic wood is more expensive than ACQ treated lumber but will last longer.

Credits: Terry DelValle

The dimensions are up to the individual because lumber is available in an assortment of sizes. For example, most backyards can accommodate a raised bed that measures 4 ' x 8'. For a basic design, let's use 2" x 8" (actual $1 \frac{112}{2}$ x 7 1/4") $x$ 8' long ACQ treated lumber (Fig. 4). In order to build a bed that is 4 ' wide $\times 8^{\prime}$ long $\times 213 / 4$ " high, purchase nine 2 " x 8" x 8' long ACQ treated lumber planks and two 4" x 4" x 6 ' long ACQ treated posts that can be cut into six 213/4" posts (one for each corner and one in the middle along the long sides). Purchase ninety 3 " long deck screws. Stainless steel screws are preferred when using ACQ treated lumber. However, if you are on a limited budget, look for screws with a coated finish guaranteed not to corrode when used with ACQ treated lumber.

Selection of a good lightweight soilless media rich in organic matter is important. Premade mixes of soilless media can be purchased by the cubic yard or in bags for easier handling. You can make your own by using one or more of these components: well-rotted compost, composted pine bark, composted manures, peat moss, perlite, and vermiculite. Depending on the components used, lime may be needed to obtain the preferred soil $\mathrm{pH}$. To determine the number of cubic yards needed, multiply length by width by height to get cubic feet and divide by 27 cubic feet to calculate cubic yards. For this example: 8' x 4' x 1.81' divided by $27=2.15$ cubic yards.

\section{Supplies needed for 4' $x 8^{\prime} \times 21 \%$ "' high raised bed}

- Nine (9) 2" x 8" x 8' long ACQ treated lumber

- Two (2) 4" x 4" x 6 ' long ACQ treated posts

- 90 (ninety) 3" long stainless steel or coated deck screws for ACQ treated lumber

- 2.15 cubic yards of lightweight soil

\section{Construction}

Cut the treated posts into six pieces measuring $213 / 4$ " to secure the inside corners of the bed and the middle along the long sides, or anchor with metal corner brackets screwed to the inside. (Another option is to cut them 24 " long and drive the additional $2 \frac{1}{4}$ " into the ground to anchor the bed.) Cut three of the lumber pieces in half (4' long) for the ends.

Move all the materials to the site and level if needed. First attach the 4' long boards to the post and then add the 8' long boards using three screws for each connection. Alter the placement of the screws that occur at right angles so they don't hit one another when going into the post. There will be three boards stacked on each side of the bed with a total height of $213 / 4$ ". Make sure the tops of the six posts are at the same height. Soil may need to be added or removed to level it. If beds are made longer, additional supports are necessary to keep the boards from buckling. 

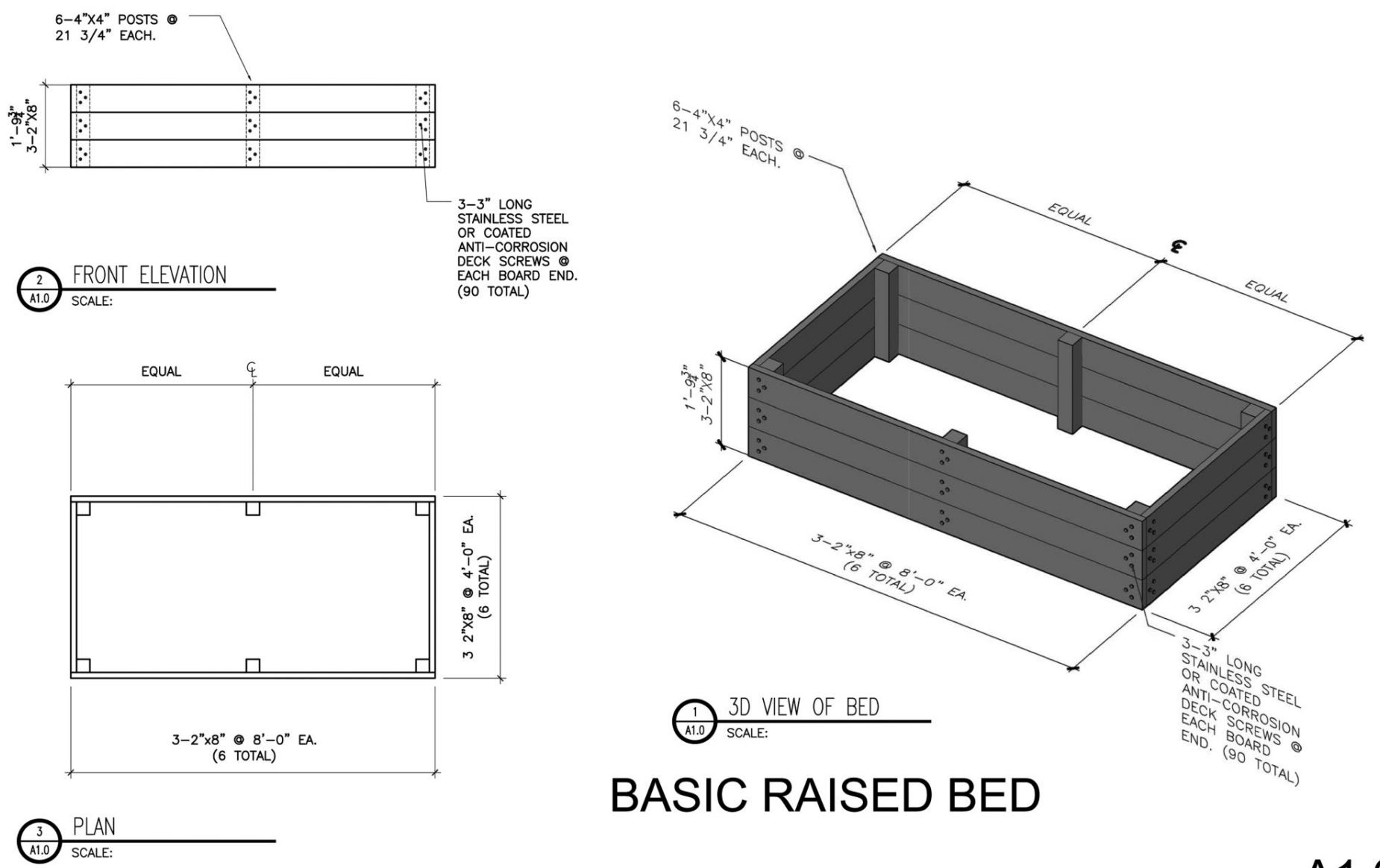

Figure 4. Example of raised bed construction.

If weeds were formerly a problem on the site, consider adding a weed barrier using four or five layers of newspaper or cardboard before adding the soilless media. Moisten the newspaper or cardboard before putting the soil in place. Install the soilless media to the very top of the bed. This may seem high, but once it settles, the level may drop by about 2".

Irrigation is critical to success since soil used in raised beds is typically well drained and may dry quickly. Install low-volume irrigation by using soaker hoses, microspray jets, or drip tubing to conserve water and keep it off the plant leaves.

\section{Planting and Maintenance}

Mix a fertilizer into the top 6" of the soilless mix. A 6-6-6, 10-10-10, or a balanced, slow-release vegetable fertilizer is suitable. The amount to use is based on the analysis, which can be found on the fertilizer label, and the square feet of the surface area. Now you are ready to plant. Follow the guidelines in the Florida Vegetable Gardening Guide (http:// edis.ifas.ufl.edu/vh021) for fertilizer rates, plant spacing, and recommended varieties. When gardening in raised beds, try planting in blocks instead of rows. Eliminate the space for rows because that area is not needed to work the garden. Now the entire garden is an intensive production area. Over time, the soil in the bed shrinks, so add soil to bring it up to the original planting level in the raised bed.

Whether you try gardening in raised beds or growing in traditional vegetable gardens, enjoy the rewards of a convenient, fresh, and nutritious food supply. 